OPEN ACCESS

Edited by:

Vincent Geenen,

University of Liège, Belgium

Reviewed by:

Arturo Ortega,

Centro de Investigación y

de Estudios Avanzados del

Instituto Politécnico Nacional

(CINVESTAV-IPN), Mexico

Susana Elba Gea,

National University of Cordoba,

Argentina

*Correspondence:

Ana Rosa Pérez

perez@idicer-conicet.gob.ar,

perez_anarosa@yahoo.com.ar

Specialty section:

This article was submitted to

Neuroendocrine Science,

a section of the journal

Frontiers in Endocrinology

Received: 27 November 2017

Accepted: 31 May 2018

Published: 14 June 2018

Citation:

Pérez AR, Morrot A, Carvalho VF, de Meis J and Savino W (2018) Role of Hormonal Circuitry Upon T Cell

Development in Chagas Disease:

Possible Implications on T Cell

Dysfunctions.

Front. Endocrinol. 9:334. doi: 10.3389/fendo.2018.00334

\section{Role of Hormonal Circuitry Upon T Cell Development in Chagas Disease: Possible Implications on T Cell Dysfunctions}

\author{
Ana Rosa Pérez ${ }^{1 *}$, Alexandre Morrot ${ }^{2,3}$, Vinicius Frias Carvalho ${ }^{4,5}$, Juliana de Meis ${ }^{5,6}$ \\ and Wilson Savino ${ }^{5,6}$
}

${ }^{1}$ Institute of Clinical and Experimental Immunology (IDICER-CONICET UNR), Rosario, Argentina, ${ }^{2}$ Faculty of Medicine, Tuberculosis Research Center, Federal University of Rio de Janeiro, Rio de Janeiro, Brazil, ${ }^{3}$ Oswaldo Cruz Institute, Oswaldo Cruz Foundation, Rio de Janeiro, Brazil, ${ }^{4}$ Laboratory of Inflammation, Oswaldo Cruz Institute, Oswaldo Cruz Foundation, Rio de Janeiro, Brazil, ${ }^{5}$ Laboratory on Thymus Research, Oswaldo Cruz Institute, Oswaldo Cruz Foundation, Rio de Janeiro, Brazil, ${ }^{6}$ National Institute of Science and Technology on Neuroimmunomodulation (INCT-NIM), Rio de Janeiro, Brazil

T cell response plays an essential role in the host resistance to infection by the protozoan parasite Trypanosoma cruzi, the causative agent of Chagas disease. This infection is often associated with multiple manifestations of T cell dysfunction, both during the acute and the chronic phases of disease. Additionally, the normal development of $T$ cells is affected. As seen in animal models of Chagas disease, there is a strong thymic atrophy due to massive death of $\mathrm{CD}^{+}{ }^{+} \mathrm{CD} 8^{+}$double-positive cells by apoptosis and an abnormal escape of immature and potentially autoreactive thymocytes from the organ. Furthermore, an increase in the release of corticosterone triggered by $T$. cruzi-driven systemic inflammation is strongly associated with the alterations seen in the thymus of infected animals. Moreover, changes in the levels of other hormones, including growth hormone, prolactin, and testosterone are also able to contribute to the disruption of thymic homeostasis secondary to T. cruzi infection. In this review, we discuss the role of hormonal circuits involved in the normal $\mathrm{T}$ cell development and trafficking, as well as their role on the thymic alterations likely related to the peripheral $T$ cell disturbances largely reported in both chagasic patients and animal models of Chagas disease.

Keywords: Chagas disease, thymus atrophy, thymocytes, hypothalamus-pituitary-adrenal axis, growth hormone, prolactin

\section{INTRODUCTION}

Chagas disease, or American trypanosomiasis, is a tropical neglected illness caused by the hemoflagellate protozoan Trypanosoma cruzi. Chagas disease transmission to humans can be classified in primary (vectorial, blood transfusion, congenital, and orally) and secondary (less frequent, such as laboratory accident, handling of infected animals, organ transplantation from infected donors, and hypothetically through sexual) routes of $T$. cruzi infection $(1,2)$. Presently, oral transmission of human Chagas disease is the most important transmission route in the Brazilian Amazon region, mainly secondary to food/beverage contamination with T. cruzi. It is noteworthy that oral transmission has been associated with high mortality and morbidity, increased prevalence and severity of the cardiac pathology (myocarditis) (3-6). Argentina, Bolivia, Colombia, Ecuador, French Guiana, and Venezuela have also reported acute Chagas disease cases associated with contaminated food consumption (7-9). 
Trypanosoma cruzi infection is presently considered as a worldwide health problem with deficiencies in treatment, absence of appropriated vaccines and world spreading $(10,11)$. The infection leads to an acute phase, with symptoms such as fever, muscle pain, swollen lymph nodes, hepatosplenomegaly, edema, tachycardia, dyspnea, pericardial effusion and inflammatory reaction at the vector's biting site of the vector (chagoma) $(2,12)$. During the acute phase, circulating parasite numbers are systemically increased, and they are able to infect several tissues and cell types, such as skeletal and cardiac myocytes, macrophages, fibroblasts, neurons and epithelial cells. For this reason, amastigote nests were already described in glands, skeletal muscle, as well as, lymphoid and nervous tissues $(11,13)$. Following recovery from the acute phase, the patient enters into a long indeterminate, latent, phase with no symptoms and very low parasitism. The latent infection may remain silent for 10-30 years. One-third of infected patients in the latent phase develop clinical symptoms as chronic cardiac dysfunction (cardiomyopathy), megacolon or megaesophagus. It is believed that chronic chagasic cardiomyopathy has an autoimmune pathophysiological component, with involvement of $\mathrm{T}$ and $B$ autoreactive cells, as well as promoted by the persistence of the parasite. At this phase, life expectancy decreases about 9 years in these clinical forms of chronic patients (14).

\section{T Cell Changes During T. cruzi Infection}

In the immune system, T. cruzi infection promotes changes in the dynamics and in the size of T lymphocyte populations, contributing to regional response in primary, including thymus and secondary lymphoid organs (15). In infected mice, the thymus suffers a strong atrophy in the acute phase, due to massive death of $\mathrm{CD}^{+} \mathrm{CD}^{+}$double-positive (DP) and $\mathrm{CD} 4^{+} \mathrm{Foxp}^{+}$regulatory T cells (Treg) by apoptosis, accompanied by an abnormal escape of immature and potentially autoreactive $\mathrm{T}$ lymphocytes from the organ $(11,16)$. Interestingly, $T$ cell abnormal escape was also documented in chronically T. cruzi-infected patients $(17,18)$. On the other hand, it is known that under physiological conditions, the re-entry of $\mathrm{CD}^{+}$and $\mathrm{CD}^{+} \mathrm{T}$ cells into the thymus is restricted to activated/memory cells (19), being driven by CCL2/ CCR2 interactions (20). Some authors speculate that the reentrance of $\mathrm{T}$ effector cells may influence the tolerance induction by promoting Treg development, since they represent the main source of IL-2 (21). Furthermore, Treg with a clear maturational phenotype were observed in the infected thymus, suggesting that they may correspond to peripheral Treg that have re-entered into the thymus (16). In any case, the physiological consequences of the Treg cell re-entry into the thymus remains undetermined.

Diverse groups have shown an expansion in secondary lymphoid organs such spleen and subcutaneous lymph nodes due to $\mathrm{T}$ and $\mathrm{B}$ cell polyclonal activation. In contrast, the mesenteric lymph nodes and Payer's patches show atrophy and T lymphocyte death $(15,22-33)$.

An increase in IL-2 production is involved in subcutaneous lymph nodes hyperplasia in T. cruzi infection $(15,31)$. Spleen and subcutaneous lymph node hypertrophy is a consequence of tissue T/B lymphocyte activation and proliferation $(15,23,31,34,35)$. Moreover, trans-sialidase, racemase, and T. cruzi DNA seem to contribute to $\mathrm{T}$ and/or $\mathrm{B}$ lymphocyte activation and cytokine production by interfering with interaction between dendritic cells and lymphocytes (36-40). In contrast to the hyperplasia seen in spleen and subcutaneous lymph nodes of infected mice, mesenteric lymph node atrophy is related to a local decrease in IL-2 and IL-4 production, with apoptotic death of T/B lymphocytes (15). In a second vein, it has been shown in the mouse model that splenectomy or mesenteric lymph node excision prior to T. cruzi inoculum increases susceptibility to infection, suggesting that these lymphocytes are involved in T. cruzi host immune response $(15,22-33)$.

\section{SYSTEMIC HORMONAL IMBALANCE IN CHAGAS DISEASE}

Endocrine and immune systems control several physiological, biochemical, and functional activities in the organism both during homeostasis, including early development and aging (41), as in pathological situations, such as infectious and metabolic diseases $(42,43)$. Immunoendocrine interactions occur through bidirectional circuits, characterized by highly specialized signaling molecules known as cytokines and hormones, respectively (44). Given the extensive diversity of interactions between endocrine and immune cells, it is conceivable that disturbances of one or more of these components of the immunoendocrine axes lead to the development and/or exacerbation of several illnesses, including Chagas disease (42).

The hormonal imbalance in patients with Chagas disease has been discussed since the discovery and description by Carlos Chagas, who divided the symptomatology of chronic form of American Trypanosomiasis according to thyroid, heart, and central nervous system disease. In fact, the inclusion of the thyroid form of the disease was based on both clinical aspects, association of goiter with myxedema, and the detection of the parasite and inflammation in thyroid during autopsy (45). Currently, it is believed that Chagas disease by itself is not able to cause goiter, but may predispose patients to develop goiter (46).

One of the main endocrine circuits studied in Chagas disease is the hypothalamus-pituitary-adrenal (HPA) axis, since the release of glucocorticoid (GC) hormones is a protective mechanism of the host against the harmful effects of pro-inflammatory cytokines (47). Acute T. cruzi infection induces increased corticosterone levels in both $\mathrm{C} 57 \mathrm{BL} / 6$ and $\mathrm{BALB} / \mathrm{c}$ mouse strains (48), indicating a hyperactivation of HPA axis. Such an increase in circulating corticosterone levels is in close correlation with the hypertrophy of adrenal glands, including its zona fasciculata, and a rise in the expression of several steroidogenic enzymes, such as cytochrome P450, family 11, subfamily A, polypeptide 1 (CYP11A1), CYP11B1, 11 $\beta$-hydroxysteroid dehydrogenase type 1 (HSD1), and steroidogenic acute regulatory protein (StAR) (49).

This HPA axis activation observed in experimental models of Chagas disease is associated with the presence of nests of $T$. cruzi amastigotes in the adrenals, as well as parasite-derived antigens in both adrenals and pituitary gland (50). Although by now, the underlyning mechanisms are not fully elucidated, the presence of T. cruzi-derived antigens (proteins, DNA, or glycolipids) in the endocrine glands of HPA axis may promote a local inflammatory response via the engagement of TLRs, as 
shown in bacterial models of infection (51). In particular, the stimulation of TLR-9, which recognizes T. cruzi DNA (52), may cause the local production of cytokines and consequent increase in the release of corticosterone, as seen in a model of sepsis (53). Similarly, TLR-2 or TLR-4 pathways might be stimulated by TLR agonists expressed by T. cruzi like GPI or GIPL anchors, respectively (54). In fact, C57BL/6 mice infected with T. cruzi showed, not only in plasma but also intra-adrenal, increased levels of TNF- $\alpha$, IL-1 $\beta$, and IL-6 (55), suggesting that these proinflammatory cytokines are involved in the hyperactivation of HPA axis at different levels.

Although infected mice presented the parasite and a pronounced inflammatory response in the pituitary gland, the systemic levels of adrenocorticotropic hormone (ACTH) are not changed $(49,50)$, suggesting that the increase in circulating corticosterone levels noted in infected mice occurs independently of ACTH. In fact, both systemic and intra-adrenal cytokine production may favor adrenal inflammation during infection, which can directly trigger and sustain an alternative way of adrenal secretion of GC, resulting uncoupled from the hypothalamic-pituitary unit (56). Structural alterations like vascular changes within the endocrine microenvironment may also lead to a transient HPA dysfunction (56). Also, local inflammation driven by the presence of T. cruzi or their antigens may promote the income of inflammatory cells. Strikingly, adrenals of infected mice showed leukocyte infiltration, characterized by the presence of $\mathrm{CD}^{+}$and $\mathrm{CD}^{+} \mathrm{T}$ lymphocytes, as well as macrophages and enhanced expression of extracellular matrix (ECM) deposition, including fibronectin and laminin (44). These ECM molecules might fix pathogen-derived antigens as well as pro-inflammatory cytokines released during immune response, thus contributing to the establishment of inflammation and sustaining GC production (56).

Pituitary hormones, including growth hormone $(\mathrm{GH})$ and prolactin (PRL), act as modulators of the immune system (57, 58). Similarly to GC, GH and PRL are considered stress-related hormones $(59,60)$, having opposing actions of GC on the viability and proliferation of thymic cells (61). In GH-/PRL-secreting GH3 cells, the infection with T. cruzi in vitro induces a reduction in the secretion of both GH and PRL (62). These results suggest that T. cruzi infection decreases GH and PRL production by the pituitary. In fact, chagasic patients showed decreased GH levels in response to glucose or insulin compared to healthy subjects (63), and mice infected with T. cruzi presented a reduction in plasma PRL levels (64). In effect, the low production of PRL by pituitary induced by T. cruzi infection seems to directly affect the high corticosterone synthesis by the adrenals (65). Interestingly, while asymptomatic patients showed a tendency to diminish the secretion of $\mathrm{GH}$, individuals with severe cardiomyopathy show increased levels of this hormone and also an altered GH/IGF-1, suggesting an imbalance in this axis (65).

Besides GC and pituitary hormones, some gonadal steroid hormones, including dehydroepiandrosterone-sulfate (DHEA-s) and testosterone, can be altered in human or experimental Chagas disease $(66,67)$. Animals infected with T. cruzi presented a reduction in serum testosterone levels in the acute phase of infection. However, histological analyses in testes, seminal vesicles, and epididymis did not reveal any differences between control and infected animals (68). In addition, T. cruzi-infected animals showed an increase in circulating levels of estradiol (67). Regarding DHEA-s levels, rats infected with T. cruzi did not alter the DHEA-s systemic levels. However, chronic chagasic patients with different degrees of myocarditis presented a marked reduction in DHEA-s levels. Interestingly, although the alterations in the levels of DHEA in animals are not seen in patients with Chagas disease, both animals and patients presented an increase in GC/DHEA-s ratio, which is important for the development of an anti-inflammatory milieu $(66,67)$.

\section{HORMONES AND THEIR RELATIONSHIP WITH THYMUS ATROPHY IN T. cruZi INFECTION}

$\mathrm{T}$ cell response plays an essential role in the host resistance to the T. cruzi infection, but sub-clinic and clinic manifestations of Chagas disease can be associated with multiple manifestations of $\mathrm{T}$ cell dysfunction (69-73). Additionally, as seen in animal models of Chagas disease, there is a strong thymic atrophy characterized by loss of thymus weight, massive death of $\mathrm{CD} 4^{+} \mathrm{CD} 8^{+}$ DP cells by caspase-dependent apoptosis (32), alterations in the double-negative (DN) T-cell population $(74,75)$, depletion of thymic Treg (16) and also an abnormal and premature escape of immature and potentially autoreactive DP and DN thymocytes from the organ $(17,26,74,76)$. Furthermore, it has been recently described that during experimental T. cruzi infection, bone marrow aplasia and a diminution in common lymphoid progenitors appear before thymic alterations (75).

Due to the possible autoimmune component of chagasic myocarditis, it is plausible to hypothesize that thymic selection mechanisms could be altered as a consequence of the infection. In this regard, in BALB/c mice, some T-cell receptor (TCR) V $\beta$ families, which under normal conditions should have undergone negative selection through apoptosis, appear in the periphery of the immune system during T. cruzi infection and might potentially conduce to autoimmune reactions (77). Nevertheless, in the same study, potentially autoimmune mature T cells were not seen within the thymus. Using an (OVA)-specific TCR transgenic system, we confirmed that the negative selection process is normal during experimental T. cruzi infection. In addition, the expression of autoimmune regulator factor (AIRE) expression and tissuerestricted antigen genes were normal in the thymus of infected animals (17). However, similarly to what is described in the murine model, activated DP T cells with an activated phenotype are found in the blood of patients with chronic Chagas disease in association with severe myocarditis (17), suggesting that some intrathymic checkpoints might be failed. This may have related to $\mathrm{T}$ cell trafficking alterations due to changes in the patterns the ECM protein deposition within the organ, expression of ECM receptors on thymocytes and thymic Tregs, as well as changes in cell migration-related cytokines $(16,32,78,79)$.

Normal T cell development is tightly controlled not only by cell-cell interactions and cytokines, but also by hormones, interacting via diversity of endocrine and paracrine pathways, acting 
on thymocytes and thymic microenvironmental cells via specific receptors $(42,80)$. Moreover, thymic cells not only respond to systemic levels of hormones but also constitutively synthetize and secrete hormones locally, such as GC, GH and PRL. In this context, disturbances in hormone levels caused by inflammation can interfere with the normal $\mathrm{T}$ cell development. Accordingly, increased evidence indicates that the thymic alterations seen during T. cruzi infection are strongly associated to hormonal imbalance, involving systemic or intrathymic axes.

\section{The HPA Axis}

It is well known that, if not controlled, systemic effects of GC on the adaptive immunity can promote immunological disturbances. The HPA axis activation, through the production and action of GC, plays a major role in protecting the host against the inflammatory acute stress caused by $T$. cruzi infection $(48,55)$. Nevertheless, immature DP thymocytes are major targets of HPA axis activation, since enhanced levels of GC seen in experimental acute T. cruzi infection induce DP thymocyte depletion through caspase-dependent apoptosis $(32,81)$. In this regard, blockade of GC receptor activity with RU486 prevented DP thymocyte apoptosis $(48,55)$ together with caspase- 8 and caspase- 9 activation (32). Interestingly, both thymic epithelial cells and DP thymocytes can also synthetize GC, suggesting that both paracrine and autocrine loops influence thymocyte survival during T. cruzi infection $(82,83)$. In addition, T. cruzi is able to infect thymic epithelial cells (84), indicating that the parasite per se may alter the local production of hormones and determining thymocyte fate. Yet, this hypothesis needs experimental confirmation.

\section{GH and PRL}

Prolactin is not only produced in the anterior pituitary gland but also in a range of tissues including adipose tissue, skin, and thymus. Actually, both GH and PRL exert relevant roles upon thymus physiology and are constitutively produced and secreted by thymocytes and thymic epithelial cells (TEC) (85-87). Increased intrathymic expression of $\mathrm{GH}$ leads to an enlarged thymus, as can be observed in transgenic mice that overexpress the hormone or in individuals treated with recombinant forms of GH (88-90). In addition, GH and IGF-1 (the hormone that mediates several $\mathrm{GH}$ effects) favor thymocyte migration, augmenting ECM deposition (85). Moreover, specific receptors for GH, IGF-1 and PRL are constitutively expressed by TEC and thymocytes, indicating autocrine and paracrine regulatory loops, in addition to the systemic effects of these hormones $(57,90)$.

The action of these anti-stress hormones is actually one of the ways that counterregulate systemically or in an organ-specific fashion, the action of the GC produced during T. cruzi infection. We have shown that PRL plays a critical role in balancing the effects of corticosterone in the thymus during T. cruzi infection $(65,74)$. In the mouse model of $T$. cruzi acute infection, we found an intrathymic cross-talk between GC receptors (GR) and PRL receptors that seems to work to counteract the effects of the infection, toward the neutralization of GC-related systemic deleterious effects on DP thymocyte survival during parasite-induced thymic atrophy. Furthermore, we showed that injection of metoclopramide (known to enhance PRL secretion by the pituitary gland), during experimental infection, preserved the thymus from atrophy during infection with T. cruzi (65). This event was associated with partial prevention of DP thymocyte apoptosis as well as thymic release of undifferentiated and potentially autoreactive DP cells to the peripheral lymphoid tissues. These findings point to a modulation of the stress-related hormonal circuits in the intrathymic T cell development during T. cruzi infection.

\section{Testosterone and DHEA}

Androgens in general, and especially testosterone, have immunosuppressive actions on the immune system, whereas the androgen DHEA seems to have immunostimulating properties, and counteracts the immunosuppressive effects of GC (91). In a second vein, it is widely accepted that sexual dimorphism is strongly related with differences in immune function and disease outcome. Concerning experimental Chagas disease, females are more resistant to infection than males, and androgen depletion improved the resistance against T. cruzi (92-94). Interestingly, in male mice, DP thymocyte death within thymic nurse cells seems to be caused by testosterone (95) and testosterone supplementation causes a diminution in thymocyte proliferation (96). Unlike GC, known to activate caspase-8 and caspase-9-mediated apoptosis in thymocytes, testosterone is able to activate thymocyte apoptosis through a caspase-3-dependent pathway (95). Studies in the rat model of T. cruzi acute infection revealed that DHEA supplementation promotes thymocyte proliferation, suggesting that DHEA treatment may prevent DP loss and other thymic alterations (96). Nevertheless, more studies are needed to evaluate the role of sex hormones in the thymic atrophy that occurs during T. cruzi infection.

\section{METABOLIC ALTERATIONS AND ADIPOKINES}

In parallel to the endocrine imbalance, animals infected with T. cruzi also show a clear metabolic disturbance, including hypoglycemia, weight loss and leptin alterations (97). It is known that, besides controlling saciety, leptin plays protective affects upon intrathymic $\mathrm{T}$ cell development under physiologic conditions $(98,99)$. Nevertheless, in acute T. cruzi-infected C57BL/6 mice, its systemic and adipose tissue derived-expression is sharply diminished, suggesting that its loss may fuel thymic atrophy (97) However, and unlike what happens in models of experimental endotoxemia (100), leptin replacement during the acute infection, while attenuating GC release, fails in reversing thymic atrophy (97). The reason of this difference should be investigated, but it is possible to speculate that thymic ObR expression during T. cruzi infection could be also diminished, as previously observed at the hypothalamic level (97). In this regard, when infected $\mathrm{db} / \mathrm{db}$ mice (that lack ObR) were reconstituted with the brain ObR, the infection was less obvious (101). These data suggest that leptin axis is dysregulated during infection. Strikingly, in chronic obese model of infection and also in human chronic disease, it was reported that adipokine disturbances are related to myocardial damage and heart autonomic dysfunction $(102,103)$, while their effects upon $\mathrm{T}$ cell dynamics has not been estimated. 


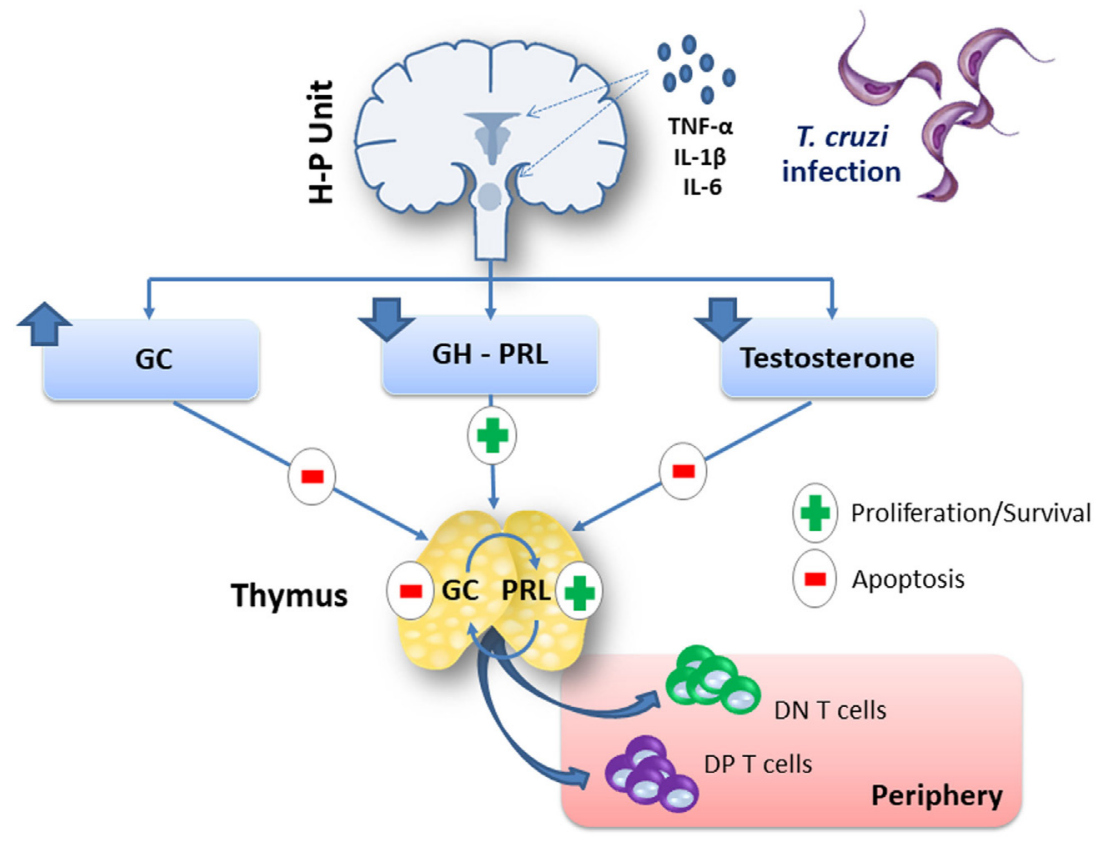

FIGURE 1 | Systemic and intrathymic hormonal imbalance affects the thymus during experimental Trypanosoma cruzi infection. Acute T. cruzi infection in mice induces a rise in plasma levels of proinflammatory cytokines, which are involved in the hyperactivation of the hypothalamus-pituitary-adrenal (HPA) axis. Proinflammatory cytokines can enhance HPA axis activation, by acting at the hypothalamus-pituitary unit and/or on peripheral glands, i.e., the adrenals. In situ inflammatory reactions caused by $T$. cruzi-derived antigens or structural changes like vascular alterations or an enhanced extracellular matrix deposition in the endocrine microenvironment may also lead to sustain glucocorticoid hormone (GC) levels. The increment of systemic and intrathymic GC levels causes thymic atrophy by depletion of $\mathrm{CD}^{+}{ }^{+} \mathrm{CD} 8^{+}$double-positive (DP) thymocytes through apoptosis. In parallel, there is an abnormal export of immature DP and double-negative (DN) T cells to the periphery of the immune system. Growth hormone (GH) and prolactin (PRL) have positive effects upon the thymus, but $T$. cruzi infection decreases GH and PRL production by pituitary cells. Male animals acutely infected with T. cruzi also present a reduction in serum testosterone levels, although DP thymocyte death seems to be induced by this androgen, whereas testosterone supplementation induced a diminution in thymocyte proliferation. Abbreviation: $\mathrm{H}-\mathrm{P}$ unit, hypothalamus-pituitary unit.

TABLE 1 | Effects of hormonal imbalance upon thymocytes during Trypanosoma cruzi infection.

\begin{tabular}{|c|c|c|c|c|c|c|c|}
\hline & GC & DHEA & PRL & GH & Testo & Leptin $\left(^{*}\right)$ & Reference \\
\hline Weight/size & $\downarrow$ & $\uparrow$ & $\uparrow$ & $\uparrow$ & $\downarrow$ & $\downarrow$ & $(18,42,44,45,53,104)$ \\
\hline Cellularity & $\downarrow$ & $\uparrow$ & $\uparrow$ & $\uparrow$ & $\downarrow$ & $\downarrow$ & $(25,42,44,46,54,55,66,73,88,104)$ \\
\hline Apoptosis of DP cells & $\uparrow$ & $\downarrow$ & $\downarrow$ & $\downarrow$ & $\uparrow$ & $\downarrow$ & $(25,42,44,46,54,55,73,87,88,104)$ \\
\hline Loss of Tregs & $\uparrow$ & ND & ND & ND & ND & ND & $(66)$ \\
\hline V $\beta$ T-cell repertoire/negative selection & ND & ND & ND & ND & ND & ND & $(19,67)$ \\
\hline Altering intrathymic cell migration & ND & ND & ND & ND & ND & ND & $(21,66,69,80)$ \\
\hline Escape of DP/DN cells to periphery & ND & ND & $\downarrow$ & ND & ND & ND & $(11,55,64,67,89,105)$ \\
\hline
\end{tabular}

DP, $C D 4^{+} C D 8^{+}$double-positive; GC, glucocorticoids; DHEA, dehidroepiandrosterone; PRL, prolactin; GH, growth hormone; Testo, testosterone; ND, not determined; $\uparrow$, increase; $\downarrow$, decrease; (*) effects caused by administration.

\section{CONCLUSION}

There is no doubt that acute T. cruzi infection induces an immunoendocrine imbalance, which somehow favors the ability of the parasite to settle in the host, and the development of distinct pathological events, among which the massive thymocyte death and consequent thymic atrophy. Yet, this is a complex network of events (summarized in Figure 1 and Table 1) that needs further investigation, including the possibility of endocrine axes being target for complementary therapeutic intervention in Chagas disease.

\section{AUTHOR CONTRIBUTIONS}

All authors contribute equally to the manuscript: AP, AM, VC, $\mathrm{JM}$, and WS.

\section{FUNDING}

This study was supported by Foncyt (PICT 2008-1892 and 2013-1892), PIP CONICET 0641, SecCyT-UNR 1MED244 and 1MED348, ASACTeI 2010-120-14 (Argentine) FAPERJ, CAPES, CNPq, FOCEM-Mercosur, Fiocruz, Inct-NIM (Brazil). 


\section{REFERENCES}

1. Dorn P, Buekens P, Hanford E. Whac-a-mole: future trends in Chagas transmission and the importance of a global perspective on disease control. Future Microbiol (2007) 2:365-7. doi:10.2217/17460913.2.4.365

2. Tarleton RL, Reithinger R, Urbina JA, Kitron U, Gurtler RE. The challenges of Chagas disease - grim outlook or glimmer of hope. PLoS Med (2007) 4(12):e332. doi:10.1371/journal.pmed.0040332

3. Barbosa-Ferreira JM, Nobre AF, Maldonado JG, Borges-Pereira J, Zauza PL, Coura JR. [Stroke in a chronic autochthonous chagasic patient from the Brazilian Amazon]. Rev Soc Bras Med Trop (2010) 43(6):751-3. doi:10.1590/ S0037-86822010000600034

4. Ianni BM, Mady C. [The sugarcane juice was delicious, but...]. Arq Bras Cardiol (2005) 85(6):379-81.

5. Vinas Albajar P, Laredo SV, Terrazas MB, Coura JR. [Dilated cardiomyopathy in patients with chronic chagasic infection: report of two fatal autochthonous cases from Rio Negro, State of Amazonas, Brazil]. Rev Soc Bras Med Trop (2003) 36(3):401-7. doi:10.1590/S0037-86822003000300013

6. Pinto AY, Harada GS, Valente V, Abud JE, Gomes F, Souza GC, et al. [Cardiac attacks in patients with acute Chagas disease in a family micro-outbreak, in Abaetetuba, Brazilian Amazon]. Rev Soc Bras Med Trop (2001) 34(5):413-9. doi:10.1590/S0037-86822001000500003

7. Sanchez LV, Ramirez JD. Congenital and oral transmission of American trypanosomiasis: an overview of physiopathogenic aspects. Parasitology (2013) 140(2):147-59. doi:10.1017/S0031182012001394

8. Noya BA, Diaz-Bello Z, Colmenares C, Ruiz-Guevara R, Mauriello L, MunozCalderon A, et al. Update on oral Chagas disease outbreaks in Venezuela: epidemiological, clinical and diagnostic approaches. Mem Inst Oswaldo Cruz (2015) 110(3):377-86. doi:10.1590/0074-02760140285

9. Toso MA, Vial UF, Galanti N. [Oral transmission of Chagas' disease]. Rev Med Chil (2011) 139(2):258-66.

10. Hotez PJ, Molyneux DH, Stillwaggon E, Bentwich Z, Kumaresan J. Neglected tropical diseases and HIV/AIDS. Lancet (2006) 368(9550):1865-6. doi:10.1016/S0140-6736(06)69764-X

11. Savino W, Villa-Verde DM, Mendes-da-Cruz DA, Silva-Monteiro E, Perez AR, Aoki Mdel P, et al. Cytokines and cell adhesion receptors in the regulation of immunity to Trypanosoma cruzi. Cytokine Growth Factor Rev (2007) 18(1-2):107-24. doi:10.1016/j.cytogfr.2007.01.010

12. Parada H, Carrasco HA, Anez N, Fuenmayor C, Inglessis I. Cardiac involvement is a constant finding in acute Chagas' disease: a clinical, parasitological and histopathological study. Int J Cardiol (1997) 60(1):49-54. doi:10.1016/ S0167-5273(97)02952-5

13. Devera R, Fernandes O, Coura JR. Should Trypanosoma cruzi be called "cruzi" complex? A review of the parasite diversity and the potential of selecting population after in vitro culturing and mice infection. Mem Inst Oswaldo Cruz (2003) 98(1):1-12. doi:10.1590/S0074-02762003000100001

14. Punukollu G, Gowda RM, Khan IA, Navarro VS, Vasavada BC. Clinical aspects of the Chagas' heart disease. Int J Cardiol (2007) 115(3):279-83. doi:10.1016/j.ijcard.2006.03.004

15. de Meis J, Morrot A, Farias-de-Oliveira DA, Villa-Verde DM, Savino W. Differential regional immune response in Chagas disease. PLoS Negl Trop Dis (2009) 3(7):e417. doi:10.1371/journal.pntd.0000417

16. Gonzalez FB, Calmon-Hamaty F, No Seara Cordeiro S, Fernandez Bussy R, Spinelli SV, D’Attilio L, et al. Trypanosoma cruzi experimental infection impacts on the thymic regulatory T cell compartment. PLoS Negl Trop Dis (2016) 10(1):e0004285. doi:10.1371/journal.pntd.0004285

17. Morrot A, Terra-Granado E, Perez AR, Silva-Barbosa SD, Milicevic NM, Farias-de-Oliveira DA, et al. Chagasic thymic atrophy does not affect negative selection but results in the export of activated CD4+CD8+ T cells in severe forms of human disease. PLoS Negl Trop Dis (2011) 5(8):e1268. doi:10.1371/ journal.pntd.0001268

18. Giraldo NA, Bolanos NI, Cuellar A, Guzman F, Uribe AM, Bedoya A, et al. Increased CD4+/CD8+ double-positive T cells in chronic Chagasic patients. PLoS Negl Trop Dis (2011) 5(8):e1294. doi:10.1371/journal.pntd. 0001294

19. Thiault N, Darrigues J, Adoue V, Gros M, Binet B, Perals C, et al. Peripheral regulatory $\mathrm{T}$ lymphocytes recirculating to the thymus suppress the development of their precursors. Nat Immunol (2015) 16(6):628-34. doi:10.1038/ ni. 3150
20. Hodge DL, Reynolds D, Cerban FM, Correa SG, Baez NS, Young HA, et al. MCP-1/CCR2 interactions direct migration of peripheral B and Tymphocytes to the thymus during acute infectious/inflammatory processes. Eur J Immunol (2012) 42(10):2644-54. doi:10.1002/eji.201242408

21. Sprent J, Surh CD. Re-entry of mature T cells to the thymus: an epiphenomenon? Immunol Cell Biol (2009) 87(1):46-9. doi:10.1038/icb.2008.88

22. de Meis J, Aurelio Farias-de-Oliveira D, Nunes Panzenhagen PH, Maran N, Villa-Verde DM, Morrot A, et al. Thymus atrophy and double-positive escape are common features in infectious diseases. J Parasitol Res (2012) 2012:574020. doi: $10.1155 / 2012 / 574020$

23. de Meis J, Mendes-da-Cruz DA, Farias-de-Oliveira DA, Correa-de-Santana E, Pinto-Mariz F, Cotta-de-Almeida V, et al. Atrophy of mesenteric lymph nodes in experimental Chagas' disease: differential role of Fas/Fas-L and TNFRI/TNF pathways. Microbes Infect (2006) 8(1):221-31. doi:10.1016/j. micinf.2005.06.027

24. Farias-de-Oliveira DA, Cotta-de-Almeida V, Villa-Verde DM, Riederer I, Meis J, Savino W. Fibronectin modulates thymocyte-thymic epithelial cell interactions following Trypanosoma cruzi infection. Mem Inst Oswaldo Cruz (2013) 108(7):825-31. doi:10.1590/0074-0276130071

25. Leite de Moraes MC, Hontebeyrie-Joskowicz M, Leboulenger F, Savino W, Dardenne M, Lepault F. Studies on the thymus in Chagas' disease. II. Thymocyte subset fluctuations in Trypanosoma cruzi-infected mice: relationship to stress. Scand J Immunol (1991) 33(3):267-75. doi:10.1111/j.1365-3083. 1991.tb01772.x

26. Mendes-da-Cruz DA, de Meis J, Cotta-de-Almeida V, Savino W. Experimental Trypanosoma cruzi infection alters the shaping of the central and peripheral T-cell repertoire. Microbes Infect (2003) 5(10):825-32. doi:10.1016/ S1286-4579(03)00156-4

27. Morrot A, Barreto de Albuquerque J, Berbert LR, de Carvalho Pinto CE, de Meis J, Savino W. Dynamics of lymphocyte populations during Trypanosoma cruzi infection: from thymocyte depletion to differential cell expansion/ contraction in peripheral lymphoid organs. J Trop Med (2012) 2012:747185. doi:10.1155/2012/747185

28. Perez AR, Berbert LR, Lepletier A, Revelli S, Bottasso O, Silva-Barbosa SD, et al. TNF-alpha is involved in the abnormal thymocyte migration during experimental Trypanosoma cruzi infection and favors the export of immature cells. PLoS One (2012) 7(3):e34360. doi:10.1371/journal.pone.0034360

29. Savino W. The thymus is a common target organ in infectious diseases. PLoS Pathog (2006) 2(6):e62. doi:10.1371/journal.ppat.0020062

30. Savino W, Mendes-Da-Cruz DA, Smaniotto S, Silva-Monteiro E, Villa-Verde DM. Molecular mechanisms governing thymocyte migration: combined role of chemokines and extracellular matrix. J Leukoc Biol (2004) 75(6):951-61. doi:10.1189/jlb.1003455

31. de Meis J, Ferreira LM, Guillermo LV, Silva EM, Dosreis GA, Lopes MF. Apoptosis differentially regulates mesenteric and subcutaneous lymph node immune responses to Trypanosoma cruzi. Eur JImmunol (2008) 38(1):139-46. doi:10.1002/eji.200737582

32. Farias-de-Oliveira DA, Villa-Verde DM, Nunes Panzenhagen PH, Silva dos Santos D, Berbert LR, Savino W, et al. Caspase- 8 and caspase- 9 mediate thymocyte apoptosis in Trypanosoma cruzi acutely infected mice. J Leukoc Biol (2013) 93(2):227-34. doi:10.1189/jlb.1211589

33. Antunez MI, Feinstein RE, Cardoni RL, Gronvik KO. Trypanosoma cruzi: $\mathrm{T}$ cell subpopulations in the Peyer's patches of BALB/c infected mice. Exp Parasitol (1997) 87(1):58-64. doi:10.1006/expr.1997.4171

34. Minoprio PM, Coutinho A, Joskowicz M, D’Imperio Lima MR, Eisen H. Polyclonal lymphocyte responses to murine Trypanosoma cruzi infection. II. Cytotoxic T lymphocytes. Scand J Immunol (1986) 24(6):669-79. doi:10.1111/ j.1365-3083.1986.tb02186.x

35. Minoprio PM, Eisen H, Forni L, D’Imperio Lima MR, Joskowicz M, Coutinho A. Polyclonal lymphocyte responses to murine Trypanosoma cruzi infection. I. Quantitation of both T- and B-cell responses. Scand J Immunol (1986) 24(6):661-8. doi:10.1111/j.1365-3083.1986.tb02185.x

36. Todeschini AR, Nunes MP, Pires RS, Lopes MF, Previato JO, MendoncaPreviato L, et al. Costimulation of host T lymphocytes by a trypanosomal trans-sialidase: involvement of CD43 signaling. JImmunol (2002) 168(10):5192-8. doi:10.4049/jimmunol.168.10.5192

37. Gao W, Wortis HH, Pereira MA. The Trypanosoma cruzi trans-sialidase is a $\mathrm{T}$ cell-independent $\mathrm{B}$ cell mitogen and an inducer of non-specific Ig secretion. Int Immunol (2002) 14(3):299-308. doi:10.1093/intimm/14.3.299 
38. Reina-San-Martin B, Degrave W, Rougeot C, Cosson A, Chamond N, Cordeiro-Da-Silva A, et al. A B-cell mitogen from a pathogenic trypanosome is a eukaryotic proline racemase. Nat Med (2000) 6(8):890-7. doi:10.1038/ 78651

39. Bryan MA, Norris KA. Genetic immunization converts the Trypanosoma cruzi B-cell mitogen proline racemase to an effective immunogen. Infect Immun (2010) 78(2):810-22. doi:10.1128/IAI.00926-09

40. Buschiazzo A, Goytia M, Schaeffer F, Degrave W, Shepard W, Gregoire C, et al. Crystal structure, catalytic mechanism, and mitogenic properties of Trypanosoma cruzi proline racemase. Proc Natl Acad Sci U S A (2006) 103(6):1705-10. doi:10.1073/pnas.0509010103

41. Hurtado-Alvarado G, Pavon L, Castillo-Garcia SA, Hernandez ME, Dominguez-Salazar E, Velazquez-Moctezuma J, et al. Sleep loss as a factor to induce cellular and molecular inflammatory variations. Clin Dev Immunol (2013) 2013:801341. doi:10.1155/2013/801341

42. Savino W, Mendes-da-Cruz DA, Lepletier A, Dardenne M. Hormonal control of T-cell development in health and disease. Nat Rev Endocrinol (2016) 12(2):77-89. doi:10.1038/nrendo.2015.168

43. e Silva PM, Carvalho VF, Cordeiro RS, Martins MA. Down-regulation of allergic responses in conditions of experimental diabetes: a role for glucocorticoids? Neuroimmunomodulation (2009) 16(1):13-8. doi:10.1159/000179662

44. Haddad JJ, Saade NE, Safieh-Garabedian B. Cytokines and neuro-immune-endocrine interactions: a role for the hypothalamic-pituitary-adrenal revolving axis. J Neuroimmunol (2002) 133(1-2):1-19. doi:10.1016/S0165-5728(02) 00357-0

45. Nova CC. entidade mórbida do homem. Mem Inst Oswaldo Cruz (1911) 3:219-75.

46. Bestetti RB, Cardinalli-Neto A, Restini CB, Couto LB. Could Carlos Chagas' assumption on the relationship between goiter and chronic Chagas heart disease be correct? A historical reappraisal. Int J Cardiol (2016) 202:410-2. doi:10.1016/j.ijcard.2015.09.052

47. Kanczkowski W, Sue M, Zacharowski K, Reincke M, Bornstein SR. The role of adrenal gland microenvironment in the HPA axis function and dysfunction during sepsis. Mol Cell Endocrinol (2015) 408:241-8. doi:10.1016/j. mce.2014.12.019

48. Roggero E, Perez AR, Tamae-Kakazu M, Piazzon I, Nepomnaschy I, Besedovsky HO, et al. Endogenous glucocorticoids cause thymus atrophy but are protective during acute Trypanosoma cruzi infection. J Endocrinol (2006) 190(2):495-503. doi:10.1677/joe.1.06642

49. Villar SR, Ronco MT, Fernandez Bussy R, Roggero E, Lepletier A, Manarin R, et al. Tumor necrosis factor-alpha regulates glucocorticoid synthesis in the adrenal glands of Trypanosoma cruzi acutely-infected mice. the role of TNF-R1. PLoS One (2013) 8(5):e63814. doi:10.1371/journal.pone. 0063814

50. Correa-de-Santana E, Paez-Pereda M, Theodoropoulou M, Kenji Nihei O, Gruebler Y, Bozza M, et al. Hypothalamus-pituitary-adrenal axis during Trypanosoma cruzi acute infection in mice. J Neuroimmunol (2006) 173(1-2):12-22. doi:10.1016/j.jneuroim.2005.08.015

51. Bornstein SR, Ziegler CG, Krug AW, Kanczkowski W, Rettori V, McCann SM, et al. The role of toll-like receptors in the immune-adrenal crosstalk. Ann N Y Acad Sci (2006) 1088:307-18. doi:10.1196/annals.1366.027

52. Bafica A, Santiago HC, Goldszmid R, Ropert C, Gazzinelli RT, Sher A. Cutting edge: TLR9 and TLR2 signaling together account for MyD88-dependent control of parasitemia in Trypanosoma cruzi infection. J Immunol (2006) 177(6):3515-9. doi:10.4049/jimmunol.177.6.3515

53. Tran N, Koch A, Berkels R, Boehm O, Zacharowski PA, Baumgarten G, et al. Toll-like receptor 9 expression in murine and human adrenal glands and possible implications during inflammation. J Clin Endocrinol Metab (2007) 92(7):2773-83. doi:10.1210/jc.2006-2697

54. Rodrigues MM, Oliveira AC, Bellio M. The immune response to Trypanosoma cruzi: role of toll-like receptors and perspectives for vaccine development. J Parasitol Res (2012) 2012:507874. doi:10.1155/2012/507874

55. Perez AR, Roggero E, Nicora A, Palazzi J, Besedovsky HO, Del Rey A, et al. Thymus atrophy during Trypanosoma cruzi infection is caused by an immuno-endocrine imbalance. Brain Behav Immun (2007) 21(7):890-900. doi:10.1016/j.bbi.2007.02.004

56. Bornstein SR, Engeland WC, Ehrhart-Bornstein M, Herman JP. Dissociation of ACTH and glucocorticoids. Trends Endocrinol Metab (2008) 19(5):175-80. doi:10.1016/j.tem.2008.01.009
57. Savino W. Prolactin: an immunomodulator in health and disease. Front Horm Res (2017) 48:69-75. doi:10.1159/000452906

58. Weigent DA. Lymphocyte GH-axis hormones in immunity. Cell Immunol (2013) 285(1-2):118-32. doi:10.1016/j.cellimm.2013.10.003

59. Torner L. Actions of prolactin in the brain: from physiological adaptations to stress and neurogenesis to psychopathology. Front Endocrinol (2016) 7:25. doi:10.3389/fendo.2016.00025

60. Peroski M, Proudan N, Grignol G, Merchenthaler I, Dudas B. Corticotropinreleasing hormone (CRH)-immunoreactive (IR) axon varicosities target a subset of growth hormone-releasing hormone (GHRH)-IR neurons in the human hypothalamus. J Chem Neuroanat (2016) 78:119-24. doi:10.1016/j. jchemneu.2016.09.005

61. de Mello-Coelho V, Gagnerault MC, Souberbielle JC, Strasburger CJ, Savino W, Dardenne $\mathrm{M}$, et al. Growth hormone and its receptor are expressed in human thymic cells. Endocrinology (1998) 139(9):3837-42. doi:10.1210/ endo.139.9.6199

62. Correa-de-Santana E, Paez-Pereda M, Theodoropoulou M, Renner U, Stalla J, Stalla GK, et al. Modulation of growth hormone and prolactin secretion in Trypanosoma cruzi-infected mammosomatotrophic cells. Neuroimmunomodulation (2009) 16(3):208-12. doi:10.1159/000205513

63. Long RG, Albuquerque RH, Prata A, Barnes AJ, Adrian TE, Christofides ND, et al. Response of plasma pancreatic and gastrointestinal hormones and growth hormone to oral and intravenous glucose and insulin hypoglycaemia in Chagas's disease. Gut (1980) 21(9):772-7. doi:10.1136/gut.21.9.772

64. Lepletier A, de Frias Carvalho V, Morrot A, Savino W. Thymic atrophy in acute experimental Chagas disease is associated with an imbalance of stress hormones. Ann N Y Acad Sci (2012) 1262:45-50. doi:10.1111/ j.1749-6632.2012.06601.x

65. Lepletier A, de Carvalho VF, Rodrigues e Silva PM, Villar S, Perez AR, Savino W, et al. Trypanosoma cruzi disrupts thymic homeostasis by altering intrathymic and systemic stress-related endocrine circuitries. PLoS Negl Trop Dis (2013) 7(11):e2470. doi:10.1371/journal.pntd.0002470

66. Perez AR, Silva-Barbosa SD, Berbert LR, Revelli S, Beloscar J, Savino W, et al. Immunoneuroendocrine alterations in patients with progressive forms of chronic Chagas disease. J Neuroimmunol (2011) 235(1-2):84-90. doi:10.1016/j.jneuroim.2011.03.010

67. Perez AR, Bertoya AA, Revelli S, Garcia F. A high corticosterone/DHEA-s ratio in young rats infected with Trypanosoma cruzi is associated with increased susceptibility. Mem Inst Oswaldo Cruz (2011) 106(4):416-23. doi:10.1590/ S0074-02762011000400006

68. Moreira A, Napimoga MH, Benatti BB, Silva GA, Rocha-Rodrigues DB, Clemente-Napimoga JT, et al. Morphological changes and EGF expression in the granular convoluted tubule cells of submandibular glands of Trypanosoma cruzi infected rats. Tissue Cell (2008) 40(4):293-8. doi:10.1016/j. tice.2008.02.004

69. de Araujo FF, Vitelli-Avelar DM, Teixeira-Carvalho A, Antas PR, Assis Silva Gomes J, Sathler-Avelar R, et al. Regulatory T cells phenotype in different clinical forms of Chagas' disease. PLoS Negl Trop Dis (2011) 5(5):e992. doi:10.1371/journal.pntd.0000992

70. Fiuza JA, Fujiwara RT, Gomes JA, Rocha MO, Chaves AT, de Araujo FF, et al. Profile of central and effector memory T cells in the progression of chronic human chagas disease. PLoS Negl Trop Dis (2009) 3(9):e512. doi:10.1371/ journal.pntd.0000512

71. Gironès N, Cuervo H, Fresno M. Trypanosoma cruzi-induced molecular mimicry and Chagas' disease. In: Oldstone MB, editor. Molecular Mimicry: Infection-Inducing Autoimmune Disease. Current Topics in Microbiology and Immunology. (Vol 296), Berlin, Heidelberg: Springer (2005).

72. Oliveira EC, Fujisawa MM, Hallal Longo DE, Farias AS, Contin Moraes J, Guariento ME, et al. Neuropathy of gastrointestinal Chagas' disease: immune response to myelin antigens. Neuroimmunomodulation (2009) 16(1):54-62. doi:10.1159/000179667

73. Albareda MC, Laucella SA. Modulation of Trypanosoma cruzi-specific T-cell responses after chemotherapy for chronic Chagas disease. Mem Inst Oswaldo Cruz (2015) 110(3):414-21. doi:10.1590/0074-02760140386

74. Lepletier A, de Almeida L, Santos L, da Silva Sampaio L, Paredes B, Gonzalez FB, et al. Early double-negative thymocyte export in Trypanosoma cruzi infection is restricted by sphingosine receptors and associated with human chagas disease. PLoS Negl Trop Dis (2014) 8(10):e3203. doi:10.1371/ journal.pntd.0003203 
75. Carbajosa S, Gea S, Chillon-Marinas C, Poveda C, Del Carmen Maza M, Fresno M, et al. Altered bone marrow lymphopoiesis and interleukin-6-dependent inhibition of thymocyte differentiation contribute to thymic atrophy during Trypanosoma cruzi infection. Oncotarget (2017) 8(11):17551-61. doi:10.18632/oncotarget.14886

76. Savino W. Neuroendocrine control of T cell development in mammals: role of growth hormone in modulating thymocyte migration. Exp Physiol (2007) 92(5):813-7. doi:10.1113/expphysiol.2007.038422

77. Mendes-da-Cruz DA, Silva JS, Cotta-de-Almeida V, Savino W. Altered thymocyte migration during experimental acute Trypanosoma cruzi infection: combined role of fibronectin and the chemokines CXCL12 and CCL4. Eur J Immunol (2006) 36(6):1486-93. doi:10.1002/eji.200535629

78. Perez AR, Bottasso O, Savino W. The impact of infectious diseases upon neuroendocrine circuits. Neuroimmunomodulation (2009) 16(2):96-105. doi:10.1159/000180264

79. Perez AR, Silva-Barbosa SD, Roggero E, Calmon-Hamaty F, Villar SR, Gutierrez FR, et al. Immunoendocrinology of the thymus in Chagas disease. Neuroimmunomodulation (2011) 18(5):328-38. doi:10.1159/000329494

80. Savino W, Dardenne M. Neuroendocrine control of thymus physiology. Endocr Rev (2000) 21(4):412-43. doi:10.1210/edrv.21.4.0402

81. Roggero E, PerezA, Tamae-Kakazu M, Piazzon I, NepomnaschyI, Wietzerbin J, et al. Differential susceptibility to acute Trypanosoma cruzi infection in $\mathrm{BALB} / \mathrm{c}$ and $\mathrm{C} 57 \mathrm{BL} / 6$ mice is not associated with a distinct parasite load but cytokine abnormalities. Clin Exp Immunol (2002) 128(3):421-8. doi:10.1046/j.1365-2249.2002.01874.x

82. Vacchio MS, Papadopoulos V, Ashwell JD. Steroid production in the thymus: implications for thymocyte selection. J Exp Med (1994) 179(6):1835-46. doi:10.1084/jem.179.6.1835

83. Qiao S, Chen L, Okret S, Jondal M. Age-related synthesis of glucocorticoids in thymocytes. Exp Cell Res (2008) 314(16):3027-35. doi:10.1016/j. yexcr.2008.06.014

84. Da Costa SC, Calabrese KS, Bauer PG, Savino W, Lagrange PH. Studies of the thymus in Chagas' disease: III. Colonization of the thymus and other lymphoid organs of adult and newborn mice by Trypanosoma cruzi. Pathol Biol (Paris). (1991) 39(2):91-7.

85. De Mello-Coelho V, Savino W, Postel-Vinay MC, Dardenne M. Role of prolactin and growth hormone on thymus physiology. Dev Immunol (1998) 6(3-4):317-23. doi:10.1155/1998/89782

86. Hattori N. Expression, regulation and biological actions of growth hormone (GH) and ghrelin in the immune system. Growth Horm IGF Res (2009) 19(3):187-97. doi:10.1016/j.ghir.2008.12.001

87. Dorshkind K, Horseman ND. The roles of prolactin, growth hormone, insulin-like growth factor-I, and thyroid hormones in lymphocyte development and function: insights from genetic models of hormone and hormone receptor deficiency. Endocr Rev (2000) 21(3):292-312. doi:10.1210/edrv.21. 3.0397

88. SmaniottoS,Ribeiro-CarvalhoMM,DardenneM,SavinoW,deMello-CoelhoV. Growth hormone stimulates the selective trafficking of thymic CD4+CD8emigrants to peripheral lymphoid organs. Neuroimmunomodulation (2004) 11(5):299-306. doi:10.1159/000079410

89. Smaniotto S, de Mello-Coelho V, Villa-Verde DM, Pleau JM, Postel-Vinay MC, Dardenne M, et al. Growth hormone modulates thymocyte development in vivo through a combined action of laminin and CXC chemokine ligand 12. Endocrinology (2005) 146(7):3005-17. doi:10.1210/en.2004-0709

90. Savino W, Dardenne M. Pleiotropic modulation of thymic functions by growth hormone: from physiology to therapy. Curr Opin Pharmacol (2010) 10(4):434-42. doi:10.1016/j.coph.2010.04.002

91. Loria RM. Antiglucocorticoid function of androstenetriol. Psychoneuroendocrinology (1997) 22(Suppl 1):S103-8. doi:10.1016/S0306-4530(97) 00005-X

92. do Prado junior JC, Leal Mde P, Anselmo-Franci JA, de Andrade juniur HF, Kloetzel JK. Influence of female gonadal hormones on the parasitemia of female Calomys callosus infected with the "Y" strain of Trypanosoma cruzi. Parasitol Res (1998) 84(2):100-5. doi:10.1007/s004360050364

93. do Prado JC Jr, Levy AM, Leal MP, Bernard E, Kloetzel JK. Influence of male gonadal hormones on the parasitemia and humoral response of male
Calomys callosus infected with the Y strain of Trypanosoma cruzi. Parasitol Res (1999) 85(10):826-9. doi:10.1007/s004360050639

94. Filipin Mdel V, Brazao V, Caetano LC, Santello FH, Toldo MP, Caetano LN, et al. Trypanosoma cruzi: orchiectomy and dehydroepiandrosterone therapy in infected rats. Exp Parasitol (2008) 120(3):249-54. doi:10.1016/j.exppara. 2008.07.012

95. Mucci J, Mocetti E, Leguizamon MS, Campetella O. A sexual dimorphism in intrathymic sialylation survey is revealed by the trans-sialidase from Trypanosomacruzi.J Immunol(2005) 174(8):4545-50.doi:10.4049/jimmunol. 174.8.4545

96. Filipin Mdel V, Caetano LC, Brazao V, Santello FH, Toldo MP, do Prado JC Jr. DHEA and testosterone therapies in Trypanosoma cruzi-infected rats are associated with thymic changes. Res Vet Sci (2010) 89(1):98-103. doi:10.1016/j.rvsc.2010.01.016

97. Manarin R, Villar SR, Fernandez Bussy R, Gonzalez FB, Deschutter EV, Bonantini AP, et al. Reciprocal influences between leptin and glucocorticoids during acute Trypanosoma cruzi infection. Med Microbiol Immunol (2013) 202(5):339-52. doi:10.1007/s00430-013-0294-1

98. Procaccini C, De Rosa V, Galgani M, Carbone F, Cassano S, Greco D, et al. Leptin-induced mTOR activation defines a specific molecular and transcriptional signature controlling CD4+ effector T cell responses. J Immunol (2012) 189(6):2941-53. doi:10.4049/jimmunol.1200935

99. Sreenivasan J, Schlenner S, Franckaert D, Dooley J, Liston A. The thymoprotective function of leptin is indirectly mediated via suppression of obesity. Immunology (2015) 146(1):122-9. doi:10.1111/imm.12488

100. Gruver AL, Ventevogel MS, Sempowski GD. Leptin receptor is expressed in thymus medulla and leptin protects against thymic remodeling during endotoxemia-induced thymus involution. J Endocrinol (2009) 203(1):75-85. doi:10.1677/JOE-09-0179

101. Nagajyothi F, Zhao D, Machado FS, Weiss LM, Schwartz GJ, Desruisseaux MS, et al. Crucial role of the central leptin receptor in murine Trypanosoma cruzi (Brazil strain) infection. J Infect Dis (2010) 202(7):1104-13. doi:10.1086/ 656189

102. Cabalen ME, Cabral MF, Sanmarco LM, Andrada MC, Onofrio LI, Ponce NE, et al. Chronic Trypanosoma cruzi infection potentiates adipose tissue macrophage polarization toward an anti-inflammatory M2 phenotype and contributes to diabetes progression in a diet-induced obesity model. Oncotarget (2016) 7(12):13400-15. doi:10.18632/oncotarget.7630

103. Barbosa-Ferreira JM, Mady C, Ianni BM, Lopes HF, Ramires FJ, Salemi VM, et al. Dysregulation of autonomic nervous system in Chagas' heart disease is associated with altered adipocytokines levels. PLoS One (2015) 10(7):e0131447. doi:10.1371/journal.pone.0131447

104. Manarin R, Lamas MC, Bottasso E, Serra E, Revelli S, Salomon CJ. Efficacy of novel benznidazole solutions during the experimental infection with Trypanosomacruzi.Parasitolint(2013)62(1):79-81.doi:10.1016/j.parint.2012. 09.001

105. Pérez AR, Morrot A, Berbert LR, Terra-Granado E, Savino W. Extrathymic CD4+CD8+ lymphocytes in Chagas disease: possible relationship with an immunoendocrine imbalance. Ann N Y Acad Sci (2012) 1262:27-36. doi:10.1111/j.1749-6632.2012.06627.x

Conflict of Interest Statement: The authors declare that the research was conducted in the absence of any commercial or financial relationships that could be construed as a potential conflict of interest.

The handling editor is currently co-organizing a Research Topic with the authors AP, WS and confirms the absence of any other collaboration.

Copyright (c) 2018 Pérez, Morrot, Carvalho, de Meis and Savino. This is an open-access article distributed under the terms of the Creative Commons Attribution License (CC BY). The use, distribution or reproduction in other forums is permitted, provided the original author(s) and the copyright owner are credited and that the original publication in this journal is cited, in accordance with accepted academic practice. No use, distribution or reproduction is permitted which does not comply with these terms. 